\title{
Novel Stromal Biomarkers in Human Breast Cancer Tissues Provide Evidence for the More Malignant Phenotype of Estrogen Receptor-Negative Tumors
}

\author{
Zahraa I. Khamis, ${ }^{1}$ Ziad J. Sahab, ${ }^{2}$ Stephen W. Byers, ${ }^{2}$ and Qing-Xiang Amy Sang1 \\ ${ }^{1}$ Department of Chemistry and Biochemistry and Institute of Molecular Biophysics, Florida State University, Tallahassee, \\ FL 32306-4390, USA \\ ${ }^{2}$ Department of Oncology, Lombardi Comprehensive Cancer Center, Georgetown University Medical Center, Washington, \\ DC 20007, USA
}

Correspondence should be addressed to Qing-Xiang Amy Sang, qxsang@chem.fsu.edu

Received 28 March 2011; Accepted 19 July 2011

Academic Editor: George E. Plopper

Copyright ( $) 2011$ Zahraa I. Khamis et al. This is an open access article distributed under the Creative Commons Attribution License, which permits unrestricted use, distribution, and reproduction in any medium, provided the original work is properly cited.

Research efforts were focused on genetic alterations in epithelial cancer cells. Epithelial-stromal interactions play a crucial role in cancer initiation, progression, invasion, angiogenesis, and metastasis; however, the active role of stroma in human breast tumorigenesis in relation to estrogen receptor (ER) status of epithelial cells has not been explored. Using proteomics and biochemical approaches, we identified two stromal proteins in ER-positive and ER-negative human breast cancer tissues that may affect malignant transformation in breast cancer. Two putative biomarkers, T-cell receptor alpha (TCR- $\alpha)$ and zinc finger and BRCA1-interacting protein with a KRAB domain (ZBRK1), were detected in leukocytes of ER-positive and endothelial cells of ER-negative tissues, respectively. Our data suggest an immunosuppressive role of leukocytes in invasive breast tumors, propose a multifunctional nature of ZBRK1 in estrogen receptor regulation and angiogenesis, and demonstrate the aggressiveness of ERnegative human breast carcinomas. This research project may identify new stromal drug targets for the treatment of breast cancer patients.

\section{Introduction}

It is proposed that stromal cells surrounding DCIS and invasive ductal carcinoma are heterogeneous undergoing genotypic and phenotypic alterations that could have occurred prior to or concurrent with alterations in adjacent cancerous epithelial cells [1]. As tumor progresses, it is accompanied by proliferation of fibroblasts, lymphocyte infiltration, and angiogenesis in surrounding stromal tissues [2]. Whether these stromal changes reflect a passive or active reaction to the malignant transformation has not been explored in sufficient depth. The concept of epithelialstromal interactions and their contributions to the development and progression of mammary neoplasia has been proposed, but these previous hypotheses emphasize stromal "reactions" to the malignant transformation of epithelial cells [3]. However, ongoing efforts are challenging the old paradigm that considers microenvironmental factors as a reactive responder rather than an interactive component. Several studies have confirmed that stromal cells, including fibroblasts, leukocytes, and endothelial cells, influence the growth, differentiation, and invasive behavior of normal mammary epithelial cells and breast carcinomas [4-7]. Recently, microenvironmental factors of mesenchymal stem cells were found to promote breast cancer metastasis in mice [8]. Transforming growth factor $\beta$ (TGF- $\beta$ ), one of the best studied extracellular cytokine, was shown to modulate the growth and oncogenesis of adjacent epithelia [9]. Moreover, studies using ionizing radiation alter the stroma in a way that promoted neoplastic potential [10]. Tumor-associated macrophages have been shown to promote angiogenesis, invasion, and metastasis $[11,12]$. Inflammation, which is 
primarily a stromal reaction, has been linked to cancer risk [13]. A noteworthy study reveals distinctive gene expression pattern with prominent expression of tumor promotionassociated genes in breast cancer-derived stromal fibroblasts as compared to normal ones [14]. These studies underscore the stromal-epithelial interface as a critical mediator of oncogenic potential. While stromal cells are influenced by the adjacent epithelium via paracrine mechanisms, they are not just responding to these stimuli but also actively affecting the fate of adjacent epithelium. These data demonstrate that targeting the tumor stromal microenvironment will be a reasonable new therapeutic strategy.

Depriving tumor cells of an essential structural and functional support by inhibiting tumor stroma may result in a more efficient tumor regression and treatment. More recent genomic characterization of tumor microenvironment was done by the purification of all major cell types from normal breast tissue, DCIS, and invasive carcinomas [3]. However, the active role of stromal component in human breast tumor development and progression in relation to the estrogen receptor status of epithelial tumor cells has not been explored. Here, we investigate the proteomic alterations of stromal cells adjacent to estrogen receptor positive or estrogen receptor negative epithelial cells that may serve as biomarkers of malignant transformation.

\section{Materials and Methods}

2.1. Tissue Preparation. Freshly frozen breast tumor specimens were collected from Southern Division of the Cooperative Human Tissue Network. Based on the pathological diagnosis of each tissue sample, six ER-positive and four ERnegative tissues were selected. Collectively, ER-positive and ER-negative specimens were minced in liquid nitrogen and processed as described by Shipitsin et al. [1]

\subsection{Cell Separation}

2.2.1. Epithelial Cells. To isolate epithelial cells from the total cell fraction: $50 \mu \mathrm{L}$ (or $10-20 \mu \mathrm{L}$ for small tumor tissue) of prewashed BerEP4 beads were added to the cells (Dynal cat no. 161.02), incubated for $8 \mathrm{~min}$ on ice with occasional "flicking" of the tube then diluted to $3-5 \mathrm{~mL}$ volume with PBE. Cells were captured on magnet for $2 \mathrm{~min}$. Captured fraction contained the luminal epithelial cells. Bound cells were washed with $3 \times 200 \mu \mathrm{L}$ PBE and then immediately frozen on dry ice. Supernatant was placed into a centrifuge tube and magnetic capturing was repeated to ensure that all bead bound cells are removed.

2.2.2. Leukocytes. 100 to $200 \mu \mathrm{L}$ of prewashed Dynabeads (equal mix of CD45 cat no. $111.53 \mathrm{D}$ and CD15 cat no. 111.37D from Invitrogen) was added to the cell suspension. Cells were then incubated for $20 \mathrm{~min}$ at $4^{\circ} \mathrm{C}$ with gentle tilting and rotation followed by magnetic separation for $2 \mathrm{~min}$. Leukocyte bound cells were washed 3 times by resuspending in PBE buffer to remove contaminating cells followed by incubation on dry ice. Unbound cells were transferred to a new centrifuge tube, and magnetic capturing was repeated to ensure that all bead bound cells are removed. Unbound cells and first wash were combined and collected by centrifugation.

2.2.3. Endothelial Cells. Collected cells were incubated with $100 \mu \mathrm{L}$ prewashed CD31 beads (cat no. 111.55D Invitrogen) for $20 \mathrm{~min}$ at $4^{\circ} \mathrm{C}$ with gentle tilting and rotation. Endothelial bound cells were washed 3 times by resuspending in PBE followed by immediate freezing on dry ice.

2.2.4. Myofibroblasts. Cells were collected by centrifugation and resuspended in $500-1000 \mu \mathrm{L} \mathrm{PBE}$ followed by the addition of $50 \mu \mathrm{L}$ of prewashed/bound CD10 beads (bind $20 \mu \mathrm{L}$ biotinylated antibody CD10 (Cat no. 13-0108-82, eBioscience, San Diego, Calif, USA) to $50 \mu \mathrm{L}$ beads from CELLection Biotin Binder Kit (Cat no. 115.33D, Invitrogen, Carlsbad, Calif, USA) in $100 \mu \mathrm{L}$ PBE and incubation on ice for 1 hour with occasional "flicking" of the tube. Myofibroblasts were then captured. Bound cells were washed with $3 \times 200 \mu \mathrm{L}$ PBE then immediately frozen on dry ice.

2.3. Protein Extraction and Quantification. Cells were lysed in $30 \mathrm{mM}$ Tris, $7 \mathrm{M}$ Urea, 4\% CHAPS, with protease inhibitors, followed by vortexing for 1 hour, then centrifugation for $15 \mathrm{~min}$ at $15,000 \times \mathrm{g}$. Supernatants were collected and quantified as described previously [15]. Briefly, microplate bicinchoninic acid (BCA) protein assay kit (Pierce, Rockford, Ill, USA) was used to determine the protein concentration using bovine serum albumin as a standard according to manufacturer's instructions. A triplicate of each sample was utilized, and the mean absorbance was taken to calculate the concentration of the protein using the standard curve.

2.4. Two-Dimensional Gel Electrophoresis. A total of $50 \mu \mathrm{g}$ of proteins were vacuum-dried and reconstituted in $200 \mu \mathrm{L}$ of rehydration buffer $(30 \mathrm{mM}$ Tris, $7 \mathrm{M}$ Urea, 4\% CHAPS, and $50 \mathrm{mM}$ DTT). Isoelectric focusing was performed using Immobilized pH Gradient (IPG) strips, pH 4 to 7 (Bio-Rad). This was followed by rehydration of the strips in $375 \mathrm{mM}$ Tris-HCL pH 8.8, $6 \mathrm{M}$ urea, 2\% SDS, and 2\% DTT for $15 \mathrm{~min}$ followed by a second equilibration in $375 \mathrm{mM}$ Tris-HCL $\mathrm{pH}$ 8.8, $6 \mathrm{M}$ urea, $2 \%$ SDS, and 2\% iodoacetamide. The 2 nd dimension of the separation was performed by placing the strips onto a $10 \%$ polyacrylamide gel as described previously [16]. Gels were electrophoresed at $50 \mathrm{~V}$ for $30 \mathrm{~min}$ then at $100 \mathrm{~V}$ till the end of separation. The cathode buffer consisted of $0.1 \mathrm{M}$ Tricine, $0.1 \mathrm{M}$ Tris- $\mathrm{HCl}, \mathrm{pH} 8.2$, and $0.1 \%$ SDS, whereas the anode buffer was composed of $0.2 \mathrm{M}$ Tris- $\mathrm{HCl}$, $\mathrm{pH}$ 8.9. Gels were fixed in $40 \%$ ethanol and $10 \%$ acetic acid and stained with SYPRO Ruby (Bio-Rad) for 3 hours at room temperature as described previously [17]. Gels were destained in $10 \%$ methanol and $7 \%$ acetic acid to decrease background staining followed by washing 3 times in $\mathrm{ddH}_{2} \mathrm{O}$. Typhoon 9410 Scanning Systems (GE Healthcare) was used to scan the gels. The excitation wavelength was $457 \mathrm{~nm}$, and the signals were detected at $550 \mathrm{~V}$. 
2.5. Trypsin Digestion and NanoLC-Q-TOF-MS/MS. Gel pieces were transferred into a 96-well ZiplateC ${ }_{18}$ (Cat no. ZPC180010, Millipore, Bedford, Mass, USA). Protein digestion and peptide recovery procedures were performed as described previously [18]. Briefly, Gel pieces were dehydrated by adding $200 \mu \mathrm{L}$ of acetonitrile to each well followed by 10 minute incubation. Full vacuum was then applied to elute the acetonitrile through the $\mathrm{C}_{18}$ resin forming the bottom of the Ziplate. Gel pieces were then rehydrated by adding $15 \mu \mathrm{L}$ of a $25 \mathrm{mM}$ ammonium bicarbonate containing $5 \mathrm{ng} / \mu \mathrm{L}$ of modified trypsin. After overnight incubation at $37^{\circ} \mathrm{C}, 8 \mu \mathrm{L}$ of acetonitrile was added to the resin. After 12 minutes of incubation, $100 \mu \mathrm{L}$ of $0.2 \%$ TFA ultrapure water solution was added to each well and incubated for 30 minutes. The 96-well plate was then placed on a vacuum plate holder to empty wells. A final washing step was performed with a $100 \mu \mathrm{L}$ of $0.2 \%$ TFA ultrapure water solution followed by vacuum to empty wells. The Zipplate was then placed upon a low retention 96-well "V" bottom plate (cat no. 2897, Corning Inc., Corning, NY, USA), and tryptic digests were eluted by adding $8 \mu \mathrm{L}$ of acetonitrile followed by centrifugation at $3000 \times \mathrm{g}$. The tryptic digest was then vacuum-dried and reconstituted in solvent A (97.9\% water, 2\% Acetonitrile, 0.1\% Formic acid (v/v/v)). NanoLC/MS/MS was performed using a Q-Star Elite (Applied Biosystems, Foster City, Calif, USA) equipped with a nanoAcquity UPLC system (Waters, Milford, Mass, USA). Sample separations were performed using a $1.7 \mu \mathrm{m}$ nanoAcquity BEH130 C18 $(100 \mu \mathrm{m} \times 100 \mathrm{~mm})$ at a flow rate of $400 \mathrm{~nL} / \mathrm{min}$. Tryptic digests were eluted using the following gradient: $100 \%$ of Solvent A (97.9\% water, 2\% Acetonitrile, 0.1\% Formic acid $(\mathrm{v} / \mathrm{v} / \mathrm{v}))$ for 1 hour; then from 100\% solvent A to $100 \%$ solvent B (2\% water, 97.8\% Acetonitrile, 0.1\% Formic acid $(\mathrm{v} / \mathrm{v} / \mathrm{v}))$ in 2 hours; A $100 \%$ solvent B flow was maintained for 1 hour followed by a return to $100 \%$ of solvent A flow in $15 \mathrm{~min}$. Mass spectrometer settings were as follows: Ion spray voltage $2300 \mathrm{~V}$, interface heater temperature $220^{\circ} \mathrm{C}$, cone voltage $20 \mathrm{~V}$, and collision energy $8 \mathrm{~V}$.

2.6. Western Blotting. $25 \mu \mathrm{g}$ of proteins extracted from different cell types were reconstituted with SDS-PAGE buffer and loaded onto a $10 \%$ polyacrylamide gel. The gel was electrophoresed at $50 \mathrm{~V}$ for $30 \mathrm{~min}$ then at $100 \mathrm{~V}$ till the end of the separation as described previously [19]. Proteins were then electroblotted onto a nitrocellulose membrane at $30 \mathrm{~V}$ overnight. Following electroblotting, the membranes were blocked with 5\% BSA in TBST buffer. Western blot analysis was then accomplished using $1 \mu \mathrm{g} / \mathrm{mL}$ dilution of ZBRK1 primary antibody (cat no. H00059348-D01P, Novus Biologicals). This step was followed by incubation with horseradish peroxidase-conjugated secondary antibody against the appropriate species. Development of the bands was accomplished by the addition of a 1 to 1 ratio of Super Signal West Pico-Stable Peroxidase Solution and Luminol/Enhancer Solution (Pierce, Rockford, Ill, USA) and by using Kodak Scientific Imaging Film (cat no. 1651496, Kodak), Fixer and Replenisher/Developer and Replenisher (Kodak cat no. 1901859) according to manufacturer's instructions.

\section{Results and Discussion}

A common diagnostic feature of human breast cancer progression from in situ to invasive tumor is the dissolution of basement membrane and the gradual disappearance of fully differentiated myoepithelial cell layer. The prevalence of genetic changes and epigenetic modifications in all cell types of the mammary gland suggest that tumor progression is a collaborative work among epithelial and stromal cells challenging the old paradigm of epithelial cell-driven tumorigenesis [3]. Polyak and $\mathrm{Hu}$ proposed two alternative models of in situ to invasive carcinoma transition [20]. The authors purported that the "escape" and "release" models may not be mutually exclusive and myoepithelial cells together with infiltrating leukocytes and myofibroblasts may affect the clonal evolution of tumor epithelial cells. Recent studies support this combined model, as focal myoepithelial cell layer disruptions were found to be associated with higher leukocyte infiltration [21]. Tumor epithelial cells overlying disrupted myoepithelial cells exhibited substantial differences from other epithelial cells in the duct [22]. They were generally estrogen receptor negative with higher proliferation rate, higher frequency of loss of heterozygosity and higher expression of invasion and cell cycle-related genes $[21,23]$. Despite these corroborating data of the effect of stromal cells on oncogenesis, our knowledge of the molecular mechanisms that govern the interactions among all cell types to induce invasion is limited. Targeting tumor stromal microenvironment may provide a promising opportunity for breast cancer prevention and treatment.

A high percentage of primary breast cancers are estrogen receptor- (ER-) positive that generally have better prognosis and are responsive to endocrine therapies [24, 25]. Unfortunately, ER-negative breast cancers are more aggressive and refractory to most therapies through a yet unknown mechanism [26]. Therefore it is urgently needed to tailor new treatments that target these cancers. Invasive breast tumors display an ER-negative phenotype [22] that is often considered to result from premalignant ER-positive breast cancers by genetic alteration, epigenetic modification [27] or ER proteasome degradation [28].

By virtue of the aggressiveness of ER-negative breast cancers and their association with focally disrupted myoepithelial cells, investigating the protein expression of ERnegative and ER-positive surrounding microenvironments may lead to identification of important targets that will enrich our understanding of malignant transformation in human breast cancer. By comparing the protein profiles of epithelial and stromal cells from estrogen receptor-negative and estrogen receptor-positive breast carcinomas using nano LC-Q-TOF-MS/MS, we were able to identify differential protein signatures among the cell types isolated from the two pathologies (Figure 1). Additionally, two putative biomarkers, $\mathrm{T}$ cell receptor alpha (TCR- $\alpha$ ) and Zinc finger and BRCA1-interacting protein with a KRAB domain (ZBRK1), were identified.

The change in the protein profile in the same cell type isolated from ER-positive and ER-negative breast cancers may explain the difference in behavior and aggressiveness 

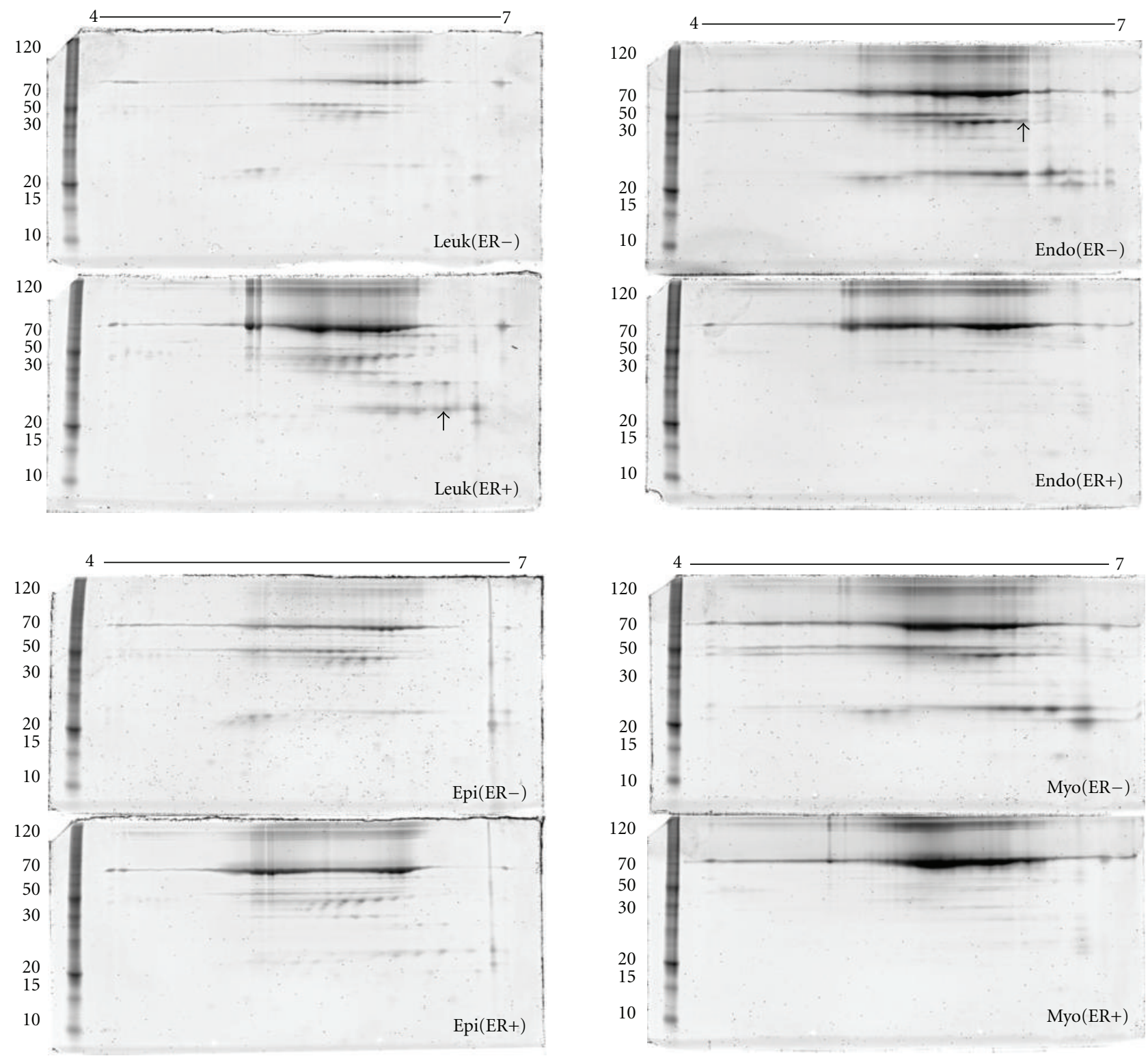

FIGURE 1: 2DE: two-dimensional gel electrophoresis (2DE) of epithelial cells (Epi), myofibroblasts (Myo), leukocytes (leuk), and endothelial cells (Endo) proteins separated from estrogen receptor-positive and estrogen receptor-negative breast cancer cells using antibody-bound magnetic beads. First dimension was performed on a pH 4 to 7 isoelectric focusing gels and the second dimension was done utilizing $10 \%$ polyacrylamide gels. Gels were stained by Sypro Ruby. Arrows point to identified proteins spots.

among the two adjacent cell clusters. Further analyses using mass spectrometry lead to the identification of two stromal proteins. TCR- $\alpha$ was detected in leukocytes of estrogen receptor-positive breast cancer cells (Figure 2), and ZBRK1 was expressed in endothelial cells of estrogen receptornegative breast tissue (Figure 3). Western blot analysis of ZBRK1 validates the higher level of expression of this protein in endothelial cells of ER-negative tissues as compared to their ER-positive counterparts (Figure 4). However, the lack of TCR- $\alpha$ antibody specific to the identified peptide did not allow further validation of the data.

Recent work expanded the historical view of cancer immunosurveillance to incorporate the potential ability of immune system to foster escape of primary tumors from immune recognition and destruction [29]. The underlying cellular and molecular mechanisms that govern the paradoxical role of immune responses in cancer progression are poorly understood. In 1863, the German pathologist Rudolf Virchow was the first to postulate a relationship between tumor development and inflammation [30]. Various experimental studies have shown that macrophages infiltrating neoplastic environment enhance development of late-stage carcinomas and pulmonary metastases [31, 32] and are associated with unfavorable prognosis. It is proclaimed that immune responses are elicited by interaction of major histocompatability complex (MHC) with TCR 


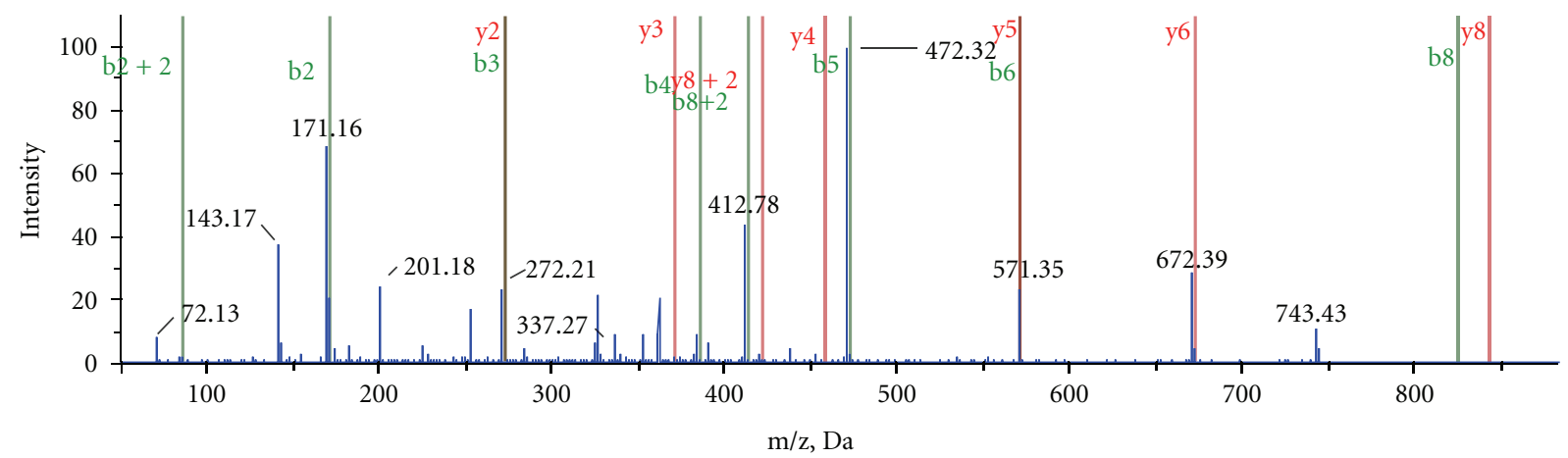

FIGURE 2: T cell receptor alpha spectra: T-cell receptor alpha was detected in the leukocytes of estrogen receptor-positive breast cancer not in that of estrogen receptor negative. LC-Q-TOF MS/MS spectra of GITLSVRP peptide generated from the trypsin digestion of TCR- $\alpha$.

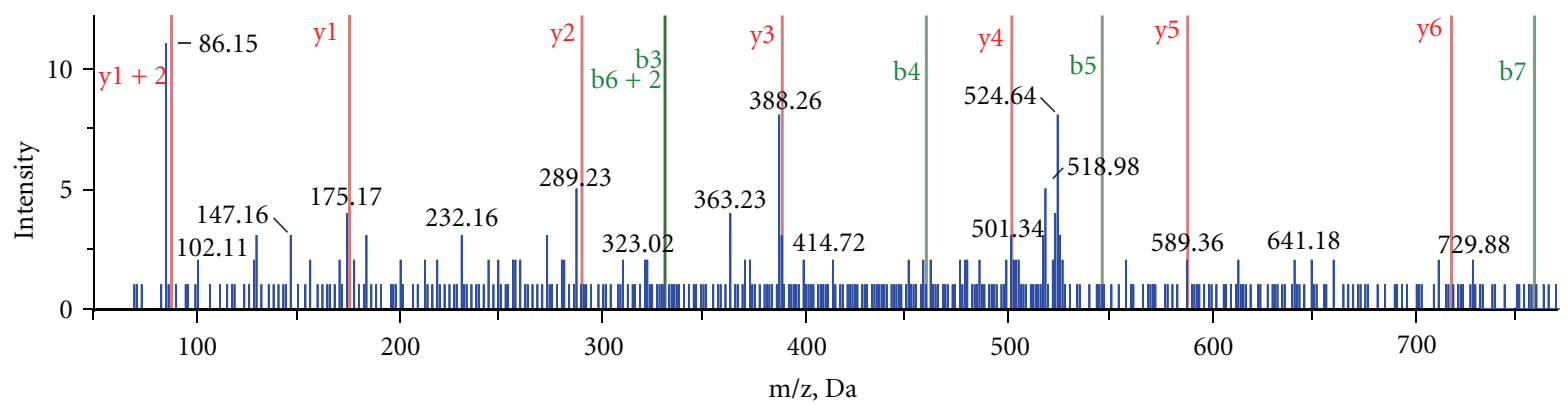

FIGURE 3: Zinc finger protein 350 spectra: Zinc finger protein 350 was identified in endothelial cells of estrogen receptor negative and not in estrogen receptor-positive breast tissue. LC-Q-TOF MS/MS spectra of LQSESLVNR peptide generated from the trypsin digestion of ZNF 350.

composed of TCR- $\alpha$ and $-\beta$ chains generated by somatic rearrangements. In view of the fact that TCR- $\alpha$ is more associated with peptides than TCR- $\beta$, it is suggested that TCR- $\alpha$ is predominantly responsible for antigen recognition [33]. The inability to detect TCR- $\alpha$ in leukocytes of ERnegative breast samples (Figure 1) highlights the inability of immune cells to recognize neoplastic cells that will bolster their escape from host immunosurveillance mechanisms. This result in part explains invasiveness of ER-negative tissue and its association with high leukocytes infiltration.

ZBRK1, also called zinc finger 350 (ZNF350), binds to target genes through its tandem zinc fingers and physically tethers with BRCA1 to form a transcriptional repression complex that blunts transcription of many DNA damage inducible genes (such as GADD45, Bax, Ki-67) that possess ZBRK1 recognition loci and are commonly regulated by BRCA1 [34]. Garcia et al. has shown altered expression of ZBRK1 in primary human breast carcinomas; however, its functional role in tumor progression is still tentative [35]. Our results reveal that ZBRK1 is expressed in endothelial cells of estrogen receptor-negative tissues, thereby suggesting a broader role of ZBRK1 in ER- $\alpha$ regulation as well as vascularization (Figure 1). The implication of ZBRK1 in ER$\alpha$ regulation has not yet been reported; however, estrogen receptor negative tissues are known to be associated with reduced BRCA1, [36]. This complex relationship between ZBRK1, BRCA1 and ER- $\alpha$ in breast carcinoma raises many important issues that remain to be resolved. The expression of ZBRK1 in endothelial cells proposes an angiogenic function. One report by Furuta et al. demonstrated that ZBRK1 reduces angiogenesis by forming a triad with BRCA1 and CtIP that impedes angiopoietin-1 (ANG1), expression in mammary epithelial cells [37]. Disruption of this complex increases ANG1 expression in epithelial cells resulting in enhanced survival of endothelial cells and, therefore, extensive vascularization. Our data shows pronounced expression of ZBRK1 in endothelial cells rather than epithelial cells suggesting that direct effect on stroma vasculature. Whether ZBRK1 affects ANG1 or other angiogenic factors in endothelial cells and whether it is in coordination with BRCA1 and ER- $\alpha$ need further investigation.

In summary, the evidence for reciprocal interactions between stromal and epithelial cells in malignant transformation of benign tumor to invasive cancer is growing steadily and can be incorporated to explain the conundrum behind the neoplastic growth. Mammary stroma in ductal carcinoma in situ (DCIS) and invasive ductal carcinoma may represent an interactive component to the neoplastic process rather than a mere reactive responder [38]. The active role of stromal component in human breast tumor development and progression in relation to the estrogen receptor status of epithelial tumor cells was not explored previously. To elucidate this role, we have isolated different stromal cells adjacent to ER-positive or ER-negative tumor epithelial cells. 


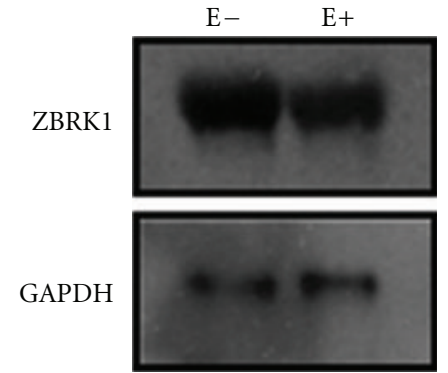

(a)

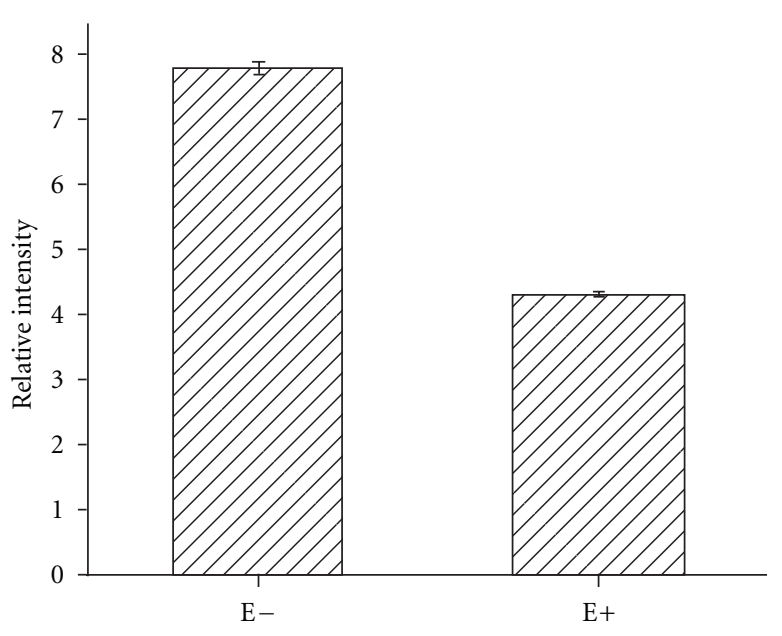

(b)

FIGURE 4: (a) Western blot of ZBRK1 in endothelial cells of estrogen receptor negative $(\mathrm{E}-)$ and estrogen receptor positive $(\mathrm{E}+)$ breast cancer tissues. (b) Bar diagram showing the relative intensity of ZBRK1 in estrogen receptor negative (E-) and positive (E+) tissues as compared the GAPDH control. ImageJ software was used for densitometric analysis and error bars represents standard error.

The protein profiles of the various cells showed differential protein signatures for each pathology suggesting potential involvement of the tumor stromal microenvironment in cancer progression. Furthermore, we were able to identify two potential biomarkers, TCR- $\alpha$ and ZBRK1, which may explain the aggressiveness of ER-negative tumors and may be responsible for disruption of the myoepithelial cell layer and its eventual disappearance during the progression of in situ tumors to invasive cancers. Future research with a much larger sample size to obtain statistically significant results and validate these findings quantitatively at transcriptional, translational, and posttranslational levels is planned.

\section{Acknowledgments}

This work was supported by Grant no. BCTR0504465 from the Susan G. Komen for the Cure Breast Cancer Foundation, grants from the Florida Breast Cancer Coalition Research Foundation, and the Florida State University to Professor Q.-X. A. Sang, and the support of Lombardi
Comprehensive Cancer Center Core Facilities (NIH P30 CA51008): Histopathology, and proteomics shared resources to Professor S. W. Byers.

\section{References}

[1] M. Shipitsin, L. L. Campbell, P. Argani et al., "Molecular definition of breast tumor heterogeneity," Cancer Cell, vol. 11, no. 3, pp. 259-273, 2007.

[2] Y. G. Man, "Focal degeneration of aged or injured myoepithelial cells and the resultant auto-immunoreactions are trigger factors for breast tumor invasion," Medical Hypotheses, vol. 69, no. 6, pp. 1340-1357, 2007.

[3] M. Allinen, R. Beroukhim, L. Cai et al., "Molecular characterization of the tumor microenvironment in breast cancer," Cancer Cell, vol. 6, no. 1, pp. 17-32, 2004.

[4] D. Radisky, C. Hagios, and M. J. Bissell, "Tumors are unique organs defined by abnormal signaling and context," Seminars in Cancer Biology, vol. 11, no. 2, pp. 87-95, 2001.

[5] M. J. Bissell and D. Radisky, "Putting tumours in context," Nature Reviews Cancer, vol. 1, no. 1, pp. 46-54, 2001.

[6] T. D. Tlsty, "Stromal cells can contribute oncogenic signals," Seminars in Cancer Biology, vol. 11, no. 2, pp. 97-104, 2001.

[7] T. D. Tlsty and P. W. Hein, "Know thy neighbor: stromal cells can contribute oncogenic signals," Current Opinion in Genetics and Development, vol. 11, no. 1, pp. 54-59, 2001.

[8] A. E. Karnoub, A. B. Dash, A. P. Vo et al., "Mesenchymal stem cells within tumour stroma promote breast cancer metastasis," Nature, vol. 449, no. 7162, pp. 557-563, 2007.

[9] N. A. Bhowmick, A. Chytil, D. Plieth et al., “TGF- $\beta$ signaling in fibroblasts modulates the oncogenic potential of adjacent epithelia," Science, vol. 303, no. 5659, pp. 848-851, 2004.

[10] S. M. Campbell, M. M. Taha, D. Medina, and J. M. Rosen, "A clonal derivative of mammary epithelial cell line COMMA-D retains stem cell characteristics of unique morphological and functional heterogeneity," Experimental Cell Research, vol. 177, no. 1, pp. 109-121, 1988.

[11] E. Y. Lin and J. W. Pollard, "Tumor-associated macrophages press the angiogenic switch in breast cancer," Cancer Research, vol. 67, no. 11, pp. 5064-5066, 2007.

[12] C. E. Lewis and R. Hughes, "Inflammation and breast cancer. Microenvironmental factors regulating macrophage function in breast tumours: hypoxia and angiopoietin-2," Breast Cancer Research, vol. 9, no. 3, article 209, 2007.

[13] C. M. Ulrich, J. Bigler, and J. D. Potter, "Non-steroidal antiinflammatory drugs for cancer prevention: promise, perils and pharmacogenetics," Nature Reviews Cancer, vol. 6, no. 2, pp. 130-140, 2006.

[14] C. F. Singer, D. Gschwantler-Kaulich, A. Fink-Retter et al., "Differential gene expression profile in breast cancer-derived stromal fibroblasts," Breast Cancer Research and Treatment, vol. 110, no. 2, pp. 273-281, 2008.

[15] Z. J. Sahab, Y. Suh, and Q. X. A. Sang, "Isoelectric pointbased prefractionation of proteins from crude biological samples prior to two-dimensional gel electrophoresis," Journal of Proteome Research, vol. 4, no. 6, pp. 2266-2272, 2005.

[16] Z. J. Sahab, Y. G. Man, S. M. Semaan, R. G. Newcomer, S. W. Byers, and Q. X. A. Sang, "Alteration in protein expression in estrogen receptor alpha-negative human breast cancer tissues indicates a malignant and metastatic phenotype," Clinical and Experimental Metastasis, vol. 27, no. 7, pp. 493-503, 2010.

[17] Z. I. Khamis, K. A. Iczkowski, Z. J. Sahab, and Q. X. Sang, "Protein profiling of isolated leukocytes, myofibroblasts, 
epithelial, basal, and endothelial cells from normal, hyperplastic, cancerous, and inflammatory human prostate tissues," Journal of Cancer, vol. 1, pp. 70-79, 2010.

[18] Z. J. Sahab, M. D. Hall, L. Zhang, A. K. Cheema, and S. W. Byers, "Tumor suppressor RARRES1 regulates DLG2, PP2A, VCP, EB1, and Ankrd26," Journal of Cancer, vol. 1, pp. 14-22, 2010.

[19] Z. J. Sahab, M. D. Hall, Y. M. Sung et al., "Tumor suppressor RARRES1 interacts with cytoplasmic carboxypeptidase AGBL2 to regulate the $\alpha$-tubulin tyrosination cycle," Cancer Research, vol. 71, no. 4, pp. 1219-1228, 2011.

[20] K. Polyak and M. Hu, "Do myoepithelial cells hold the key for breast tumor progression?" Journal of mammary gland biology and neoplasia, vol. 10, no. 3, pp. 231-247, 2005.

[21] Y. G. Man and Q. X. A. Sang, "The significance of focal myoepithelial cell layer disruptions in human breast tumor invasion: a paradigm shift from the "protease-centered" hypothesis," Experimental Cell Research, vol. 301, no. 2, pp. 103-118, 2004.

[22] Y. G. Man, T. Shen, J. Weisz et al., "A subset of in situ breast tumor cell clusters lacks expression of proliferation and progression related markers but shows signs of stromal and vascular invasion," Cancer Detection and Prevention, vol. 29, no. 4, pp. 323-331, 2005.

[23] Y. G. Man, L. Tai, R. Barner et al., "Cell clusters overlying focally disrupted mammary myoepithelial cell layers and adjacent cells within the same duct display different immunohistochemical and genetic features: implications for tumor progression and invasion," Breast Cancer Research, vol. 5, no. 6, pp. R231-R241, 2003.

[24] W. L. McGuire, "Hormone receptors: their role in predicting prognosis and response to endocrine therapy," Seminars in Oncology, vol. 5, no. 4, pp. 428-433, 1978.

[25] C. K. Osborne, "Steroid hormone receptors in breast cancer management," Breast Cancer Research and Treatment, vol. 51, no. 3, pp. 227-238, 1998.

[26] M. S. Sheikh, M. Garcia, P. Pujol, J. A. Fontana, and H. Rochefort, "Why are estrogen-receptor-negative breast cancers more aggressive than the estrogen-receptor-positive breast cancers?" Invasion and Metastasis, vol. 14, no. 1-6, pp. 329336, 1994.

[27] A. T. Ferguson, R. G. Lapidus, S. B. Baylin, and N. E. Davidson, "Demethylation of the estrogen receptor gene in estrogen receptor-negative breast cancer cells can reactivate estrogen receptor gene expression," Cancer Research, vol. 55, no. 11, pp. 2279-2283, 1995.

[28] M. Stoner, B. Saville, M. Wormke, D. Dean, R. Burghardt, and S. Safe, "Hypoxia induces proteasome-dependent degradation of estrogen receptor $\alpha$ in ZR-75 breast cancer cells," Molecular Endocrinology, vol. 16, no. 10, pp. 2231-2242, 2002.

[29] V. Shankaran, H. Ikeda, A. T. Bruce et al., "IFN $\gamma$, and lymphocytes prevent primary tumour development and shape tumour immunogenicity," Nature, vol. 410, no. 6832, pp. 1107-1111, 2001.

[30] H. David, "Rudolf Virchow and modern aspects of tumor pathology," Pathology Research and Practice, vol. 183, no. 3, pp. 356-364, 1988.

[31] E. Y. Lin, A. V. Nguyen, R. G. Russell, and J. W. Pollard, "Colony-stimulating factor 1 promotes progression of mammary tumors to malignancy," Journal of Experimental Medicine, vol. 193, no. 6, pp. 727-739, 2001.

[32] J. W. Pollard, "Tumour-educated macrophages promote tumour progression and metastasis," Nature Reviews Cancer, vol. 4, no. 1, pp. 71-78, 2004.
[33] T. Yokosuka, K. Takase, M. Suzuki et al., "Predominant role of $\mathrm{T}$ cell receptor (TCR)- $\alpha$ chain in forming preimmune TCR repertoire revealed by clonal TCR reconstitution system," Journal of Experimental Medicine, vol. 195, no. 8, pp. 9911001, 2002.

[34] L. Zheng, H. Pan, S. Li et al., "Sequence-specific transcriptional corepressor function for BRCA1 through a novel zinc finger protein, ZBRK1," Molecular Cell, vol. 6, no. 4, pp. 757$768,2000$.

[35] V. Garcia, G. Domínguez, J. M. García et al., "Altered expression of the ZBRK1 gene in human breast carcinomas," Journal of Pathology, vol. 202, no. 2, pp. 224-232, 2004.

[36] J. R. Marks, G. Huper, J. P. Vaughn et al., "BRCA1 expression is not directly responsive to estrogen," Oncogene, vol. 14, no. 1, pp. 115-121, 1997.

[37] S. Furuta, J. M. Wang, S. Wei et al., "Removal of BRCA1/ CtIP/ZBRK1 repressor complex on ANG1 promoter leads to accelerated mammary tumor growth contributed by prominent vasculature," Cancer Cell, vol. 10, no. 1, pp. 13-24, 2006.

[38] F. Moinfar, Y. G. Man, L. Arnould, G. L. Bratthauer, M. Ratschek, and F. A. Tavassoli, "Concurrent and independent genetic alterations in the stromal and epithelial cells of mammary carcinoma: implications for tumorigenesis," Cancer Research, vol. 60, no. 9, pp. 2562-2566, 2000. 


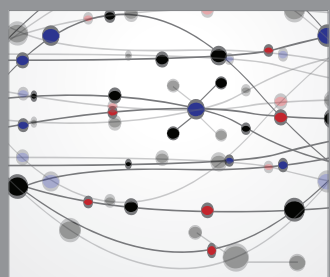

The Scientific World Journal
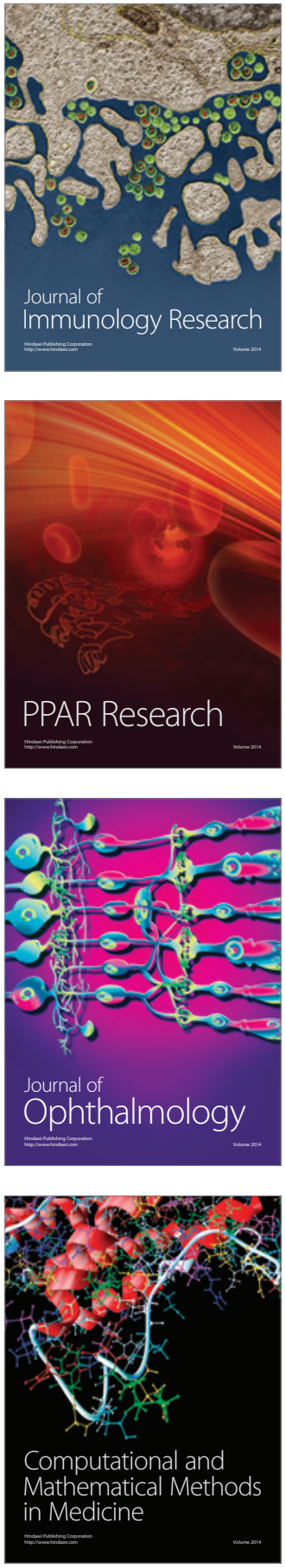

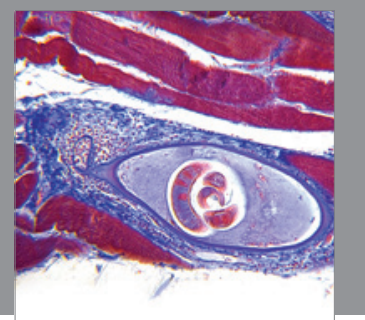

Gastroenterology

Research and Practice
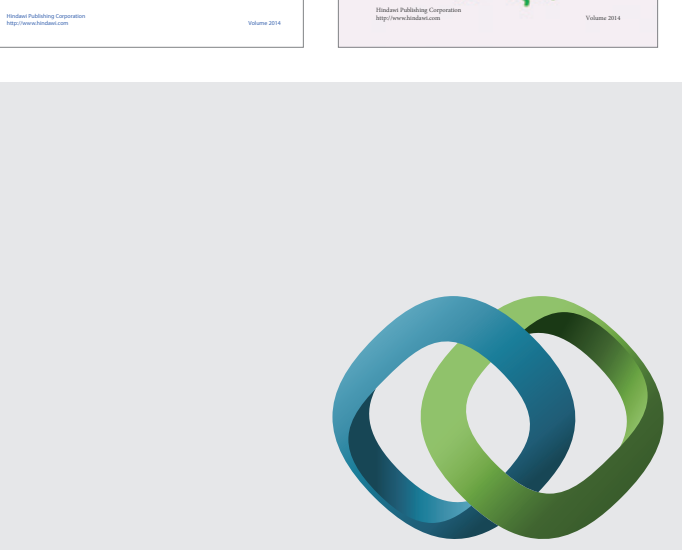

\section{Hindawi}

Submit your manuscripts at

http://www.hindawi.com
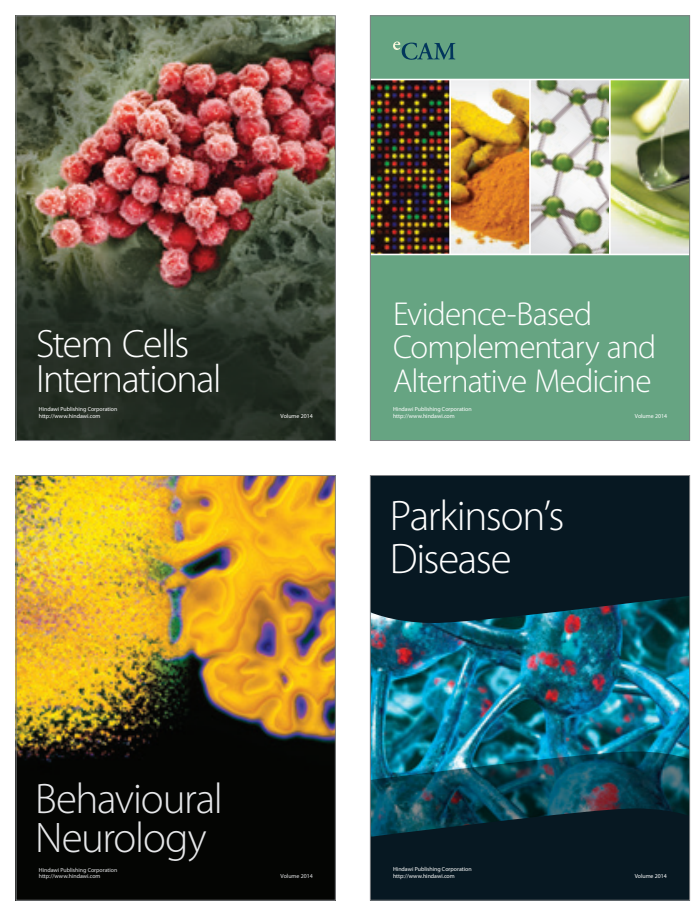

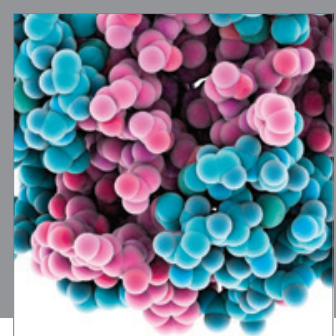

Journal of
Diabetes Research

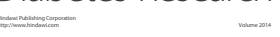

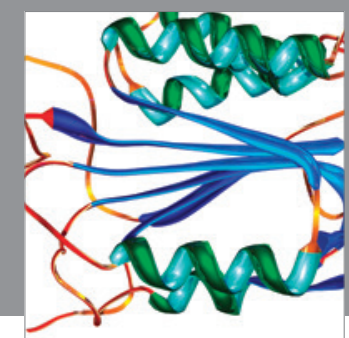

Disease Markers
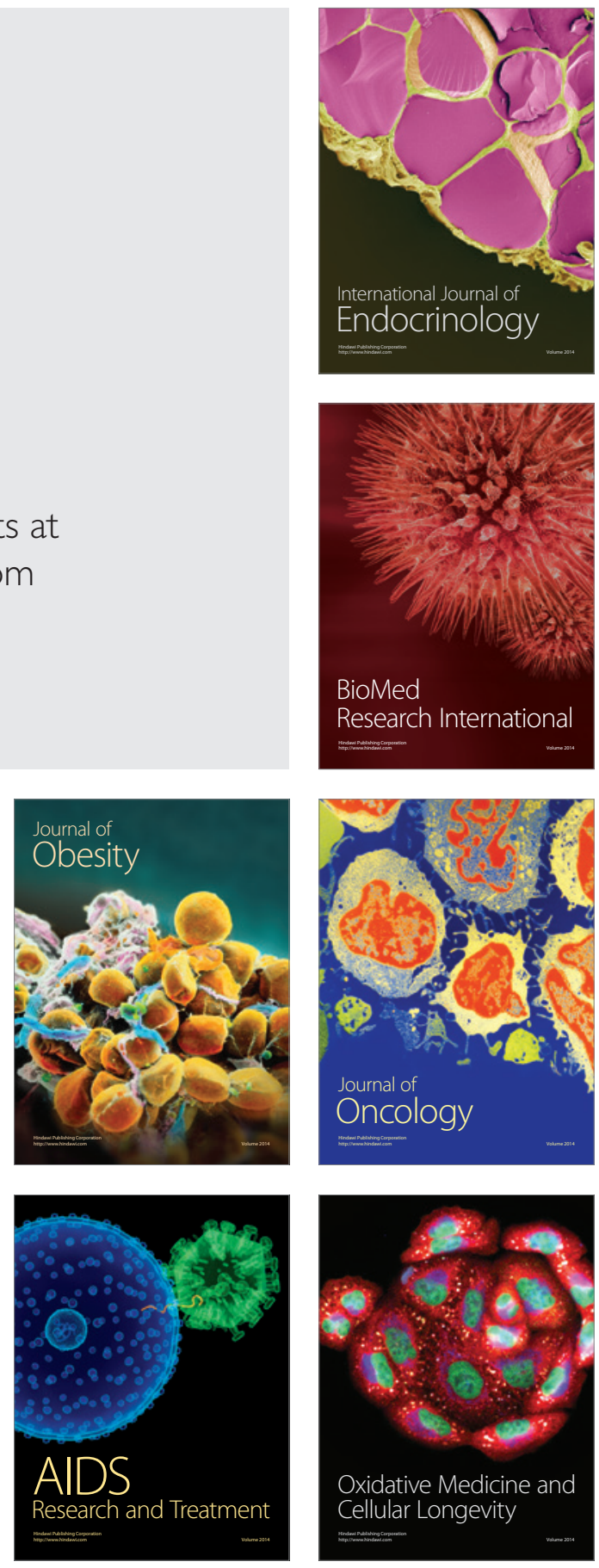